\title{
Developing Cross-Cultural Awareness in IT: Reflections of Australian and Chinese Students
}

\author{
Anne Venables, Grace Tan, and Iwona Miliszewska \\ Victoria University, Melbourne, Victoria, Australia
}

\author{
Anne.Venables@vu.edu.au Grace.Tan@vu.edu.au \\ Iwona.Miliszewska@vu.edu.au \\ Executive Summary
}

To succeed within the increasingly global context of their work environment, today's IT professional needs to be equipped with both cutting-edge technical skills and a strong repertoire of "soft" skills. An important and often unrecognized soft skill is an appreciation of how various IT issues impact upon different peoples and what constitutes an acceptable professional practice in different societies.

Australian IT students need to develop an appreciation of the impact of culture on IT issues in their own society and beyond. In particular, students require a global perspective on the impact of culture on responses to ethical dilemmas, security challenges, and privacy threats in the practice of their profession. The challenge for IT educators is how best to develop cross-cultural professional awareness in students.

This article reports on the inaugural implementation of an innovative approach aimed at developing cross-cultural awareness in undergraduate IT students. The approach comprises formative assessment tasks based on real-life IT scenarios and work in culturally mixed students teams while immersed in a culturally different society (Australian students in China in this case). The article outlines the reflections of the Australian and Chinese students participating in the experience and comments on the perceived effectiveness of the approach. Student reflections pertain to two themes: one on privacy and social freedom, and another on cross-cultural awareness. The reflections endorsed the benefits of the approach reported in this article and, in themselves, are a further encouragement for planned future exchanges.

Keywords: cultural awareness, information technology, professional skills, Australia, China.

\section{Introduction}

In Information Technology (IT) roles, there is an increasing emphasis on employees having "soft skills", i.e. people skills. While technical knowledge is essential, it is also important for IT pro-

Material published as part of this publication, either on-line or in print, is copyrighted by the Informing Science Institute. Permission to make digital or paper copy of part or all of these works for personal or classroom use is granted without fee provided that the copies are not made or distributed for profit or commercial advantage AND that copies 1) bear this notice in full and 2) give the full citation on the first page. It is permissible to abstract these works so long as credit is given. To copy in all other cases or to republish or to post on a server or to redistribute to lists requires specific permission and payment of a fee. Contact Publisher@InformingScience.org to request redistribution permission. fessionals to be able to relate to the requirements of the users, manage projects, work with teams, and, often, work in a global professional context. According to the 2006 report of the Department of Communications, Information Technology and the Arts (DCITA) (2006), titled "Building Australian ICT skills", IT will continue to be increasingly embedded in business, and IT professionals will need to work in multidisciplinary 
teams which will require problem solving abilities, negotiation skills, and a capability to understand the needs of customers and project colleagues. Moreover, the report indicates relationship management will grow as one of the main areas of expertise of the IT profession. This will require IT professionals to acquire skills in "managing intangibles, negotiating among different parties and coordinating outcomes among geographically distributed parties with different work agendas and cultures" (DCITA, 2006, pp. 51-52); this will include managing relationships between overseas service providers and domestic customers.

Globalization, a reality of the 21st century, is enabling the progressive merging of international markets and the dissolution of economic borders (Altback \& Knight, 2007; Hutchings, Jackson, $\&$ McEllister, 2002). Thus, graduates are likely to work offshore in their future professional lives so it is incumbent on education programs to prepare students to undertake job assignments anywhere in the world.

Mobility is another growing trend among the IT workforce (Joseph, Boh, Ang, \& Slaughter, 2012). Australian IT professionals are expected to travel to work overseas and IT professionals born overseas come to work in Australia; they currently account for $40 \%$ of the national IT workforce (Multimedia Victoria, 2010). Hence, there is an even more compelling need to incorporate international perspectives and cross-cultural awareness into the development of professional skills in students (Forsey, Broomhall, \& Davis, 2011). However, how should this cross-cultural professional awareness be embedded in IT curricula? Research suggests that study abroad experiences help expand student outlooks and increase their intercultural competencies (Dwyer \& Peters, 2004; Forsey et al., 2011; Nunan, 2006).

Many traditional IT education programs expend effort in developing professional awareness within their home culture but rarely expose students to the professional norms of other societies. This is particularly true for Australian students who are trained within a traditional Western education system, yet they are likely to have professional lives within the culturally diverse Asia-Pacific rim. Thus, students who gain awareness of the region's cultures in a meaningful professional experience would be most advantaged in their job readiness.

This article suggests an answer to the important question of how best to develop cross-cultural professional awareness in students. It outlines an approach to the development of this awareness through a learning strategy which examines Western and Eastern cultural responses to IT case studies. The article describes the first implementation of the approach at Victoria University in Australia with a cohort of IT students in 2012 conducted in collaboration with a university in China; it includes the Australian and Chinese students' reflections on the benefits of their shared learning experience.

\section{The Approach}

Most IT programs include several units of study designed to incrementally build soft professional skills in their students: skills such as teamwork, verbal and written communication, and networking. The demands of globalization require that cross-cultural awareness be included as a necessary component of the suite of soft skills to be developed in the delivery of an IT program.

When designing IT curricula, a suitable framework unit should be identified to target crosscultural awareness development. In the instance outlined in this article, the core unit of study selected was "Security, Privacy and Ethics", within the Bachelor of IT (Network and Systems Computing) at Victoria University. The unit introduces topical, contemporary, and often controversial issues, and it affords students the opportunity to examine ethical dilemmas, security challenges, and privacy concerns brought about through the use of IT in society. In particular, the unit highlights that IT technologies, systems, and applications are no longer constrained by national 
borders, and it includes case studies where strong cultural differences can influence responses to IT issues.

A feature of the unit is the examination of professional IT issues within Australian society and, for comparison, a culture within the Asia-Pacific rim. The Asia-Pacific region's cultures form a relevant pool of societies for Australian students to make comparisons with their own, particularly as the economic growth of the region is being fueled by the spread of IT (Television for Education, 2012) and many Australian IT graduates are likely to find themselves working there. As an emerging political super power within the region, China is of particular interest; it is one of Australia's major trading partners and the growth of the Chinese middle class is fuelling demand for Australia's technical expertise.

There are differences between some of the cultural norms of Australia and China; what may be viewed as harmless information sharing in one country, might be regarded as privacy or security concern in the other (Feng \& Hughes, 2009). In China, private data is data that others should not know about, such as information about family property or one's love life. In Australian and other Western cultures, the list of items considered to be sensitive personal data is much more comprehensive and can include salary, religion, a woman's age, marital status, sexual orientation, and political preference.

There is a large body of literature supporting the use of assessment to drive learning outcomes (Boud \& Falchikov, 2007). Formative assessment provides opportunities for students to learn through the process of undertaking an assigned task, and we use it to encourage students to examine their own understandings of IT in the Australian and other societies. An example in its simplest form could be an assignment requiring students to research IT scenarios in another society; students would be expected to identify the security issues and privacy concerns and to discuss differences between the response taken in the other society and the students' own. Ideally, students should gain firsthand exposure of the target society whilst completing their assessments.

Thus, the development of the proposed approach to incorporating cultural perspectives into the IT curriculum was driven by the intention to achieve the best possible outcome by combining formative assessment with immersion in a regional Asia-Pacific culture. It capitalizes on much educational research advocating the use of working in culturally mixed teams when undertaking groupwork (Kimmel \& Volet, 2009; Strang, 2010; Trahar \& Hyland, 2011). The approach, as detailed in Venables, Miliszewska, and Tan (2012), incorporates four integral elements:

1. formative assessment tasks where the assessment tasks guide learning experiences that promote reflections of the two contrasting cultures, one western and one eastern;

2. a real-life IT context, where students examine real-life IT situations and analyze the issues and differences between the responses of their own society and the different society;

3. immersion within the target society where Australian students participate in a shortterm study visit to a university within a contrasting society; and,

4. working in culturally mixed teams -Australian and foreign students work together on the assessment task.

For the first implementation of this approach, China was identified as a target society. For Australian students, China is an intriguing case study of contrasts to examine; unlike Australia, it has a long cultural history and a political system that tends to control access to online information. The formative assessment task was to be centered on one of several IT scenarios and it was broken into two components: the first part to be conducted in Australia, and the second part to be completed together with Chinese students while on a study visit in China. 
For the first component of the assessment, Australian students were asked to read and discuss one of several controversial situations using current IT case studies concerning security challenges, threats to privacy, and ethical issues within a western context. From their discussions, students distilled the issues, explored the various aspects, commented on possible solutions, and decided an appropriate response in their own society. For the second component of the assessment, a study visit was organized so that Australian and Chinese IT students could gain a more comprehensive perspective of the role of IT in their respective cultures. A structured program of activities ensured that all students had opportunities to discuss security and privacy issues, to engage in teamwork, to have practice in verbal and presentation skills, and network across cultural barriers. Any selected scenario needed to be culturally sensitive and avoid topics that could be considered inappropriate or too contentious for student discussion, for instance, some topics on ethics and professional behaviors, particularly if they were related to government policy. Close liaison with the Chinese host academics ensured the selection of appropriate scenarios.

\section{The Implementation}

The first study visit to implement the proposed approach was undertaken in April, 2012 when Victoria University students travelled to our partner institution, Shanghai Maritime University, in China for ten days. The visit offered a prized opportunity for the Chinese students selected to participate in the project to practice communication skills with native English speakers using the case study scenarios as a focus. English language competency is highly regarded by Chinese academics and their students. Academics at the host university selected for the project their most competent student communicators from a pool of eager candidates. Prior to the visit, we sent to our partner institution a set of case studies so that the participating Chinese students could examine those in preparation for our visit.

Our visit commenced with two days of local orientation activities for the Australian students; the first day was an organised tour of local cultural attractions, and on the second day, students were free to explore on their own. On the third day, the Australian students travelled to Shanghai Maritime University to meet their Chinese counterparts. They participated in local campus orientation and formed cross-cultural teams of four students, two Australian and two Chinese, to undertake the second component of the assessment task. Over the following days, teams distilled the issues, discussed possible solutions, and decided the appropriate response for their own society.

Each team discussed only one of several IT scenarios that had been previously assigned. The discussion centered on how the situation raised by their scenario would be resolved in Australia and in China. As an example, "The Football Broadcast War" case study involved the use of playback technologies to rebroadcast 'live' football games, as described in a newspaper article (http://www.footballnation.com.au/afl/afl-issues/the-football-broadcast-war/). In this case study, Optus, a telecommunications company, taped and rebroadcasted matches on a few seconds delay allowing its subscribers to access live football game coverage free of charge. Telstra, a competitor telecommunication company, claimed that Optus had infringed their copyright by providing Optus customers a free viewing of live football matches. Telstra had paid \$153 million for exclusive rights to the broadcasts. Discussions between the Australian students and their Chinese counterparts in examining the "The Football Broadcast War" case study revealed differences in how both cultures viewed the issue. Australian students felt that there were two separate services being supplied. Telstra customers were paying for a premium and immediate service. Optus customers had a lesser service in the small time delay, and therefore they should not be charged for the service. According to the Australian students, Optus had not infringed Telstra's copyright but rather Optus was simply taking advantage of playback technologies to provide the service for free. In addition, Australian students saw attempts to restrict the use of playback technologies as a dangerous step towards censorship. In contrast, Chinese students saw the matter quite differently. 
They argued that Telstra had paid for the exclusive rights to football games, regardless of the broadcast technologies being used. Having made such a large investment, Chinese students believed that Telstra needed protection from the government to ensure their financial interests; they had difficulty in understanding how Telstra's rights were not automatically given protection in Australia.

All teams prepared reports on the respective case studies and their discussions. Each team gave a joint presentation on how their IT scenario would be handled in Australia and in China. In their talks, students highlighted the commonalities and differences in the ways their own societies would respond to the scenarios. As each group had a different case study, much was learnt about the role of IT in both societies, as the presentations elicited many questions and comments from the audience of Chinese and Australian students. The assessment panel, composed of both Australian and Chinese IT academics, found all the final presentations to be of an exceptionally high standard and all agreed that the assessment task had been an enriching learning experience for all.

For the Australian students, living on campus and eating local food whilst enjoying the genuine friendship of their Chinese buddies was as much of a learning experience as that prescribed by their assessment. While staying at Shanghai Maritime University, the on-campus experience was quite different to that experienced in Australia. Shanghai Maritime University is a specialist Chinese university devoted to studying marine logistics and technologies and is located many kilometres away from the Shanghai city. Victoria University is located in the capital city, Melbourne, and most of its students commute daily from the surrounding suburbs. All participants expressed their thorough involvement and enjoyment in the cultural exchange and they have reported on the many lessons learnt through the experience.

\section{Student Reflections}

It is very difficult to gauge the extent to which cross-cultural awareness has been developed by this assessment; literature does not point to any objective measure that could be used and such measures are yet to be developed. As well, it is often the case that students who opt to participate in cross-cultural experiences have difficulty in articulating what they have learnt from the exchange (Forsey et al., 2011). To help assist students in their contemplations of the activities and to "measure" the development of the cross-cultural awareness in some way, all students, Australian and Chinese alike, have been asked to reflect on their experiences of the study tour and the joint assessment task. Reflective practice of learning experiences has become increasingly popular in all areas of education as a mechanism to encourage deeper learning through critical reappraisals (Light, Cox, \& Calkins, 2009; Reynolds, 2011).

A selection of the student responses, reproduced verbatim, is presented for illustration. Collectively, we noted two emerging themes: one on privacy and social freedom, and another on developing cross-cultural awareness. We have organised the student responses according to these themes and each paragraph comes from a different student; responses have been prefixed as (Aus) for Australian students, and (Chn) for Chinese students.

\section{On Privacy and Social Freedom}

(Aus) Having only experienced life in Australia before this trip, the study tour was a real eye opener for me. I learned quickly that the way things are done overseas are quite different to how we do them at home. I gained an understanding of Chinese culture and came to realize that we take for granted some of the things that are foreign to the Chinese. An example of this is social freedom, we are allowed to speak our minds on internet forums and social networking sites whereas all of this is policed by the Chinese government. 
(Chn) Through the week's contact, I discovered that our Chinese way of thinking and our habits and the purpose of education are very different from the Australian way.

(Aus) This trip has helped me pick up on the more subtle aspects of the Chinese way of thinking and Chinese culture. There are many things I experienced that I don't feel like I could have expected beforehand or have learnt about without being there and living through the experiences I have now had. An excellent example of this was when first meeting my [Chinese] buddy after she had finished taking me on a short tour of the campus we had to go up to my room to pick something up. Once at the foot of my door I opened it up and walked inside to gather my things only to notice that she was waiting outside in the hallway. I motioned for her to come in but she wouldn't without asking me first three times if it was okay if she entered. In Australia I had never found this kind of privacy to be a very big deal but apparently in China it was taken pretty seriously to let someone enter your room.

(Aus) I learned that government also plays a massive part in Chinese culture. They mould the society into something quite different from that in Australia. It seems that people don't really receive any help from the government in the form of financial aid and I believe that it is because of this, people seem to have more drive to succeed.

(Chn) My topic was about Facebook's facial recognition system. Everyone began to talk about this topic. I found it strange but interesting. We exchanged out thoughts on the topic, and after the exchange we came to know our topic and become friends.

(Aus) In contrast to this fact when undertaking the preparations for the presentation we found out that when it comes to social networks and things to do with the internet the Chinese tend to care very little about privacy.

\section{On Developing Cross-Cultural Awareness}

(Aus) I have never travelled before and travelling overseas and exploring different cultures has never been high on my priority list. Travelling to China has given me some perspective as to what goes on around the world and how things can be so different to Australia. The difference between our cultures and having to learn and adapt to a different one was an experience I'll never forget, something I definitely want to experience again.

(Aus) I feel that I have had a deeper cultural connection with China. Spending most of my time with a group of students from Shanghai Maritime University in China has given it a more authentic feel as I know that I am truly experiencing the country in the same way that they themselves do on a daily basis. This kind of experience is hard to come across.

(Chn) It has changed my world view and how I see life. Now I have a better understanding of the outside world and how people of the same ages live, and I believe it has an impact on my outlook on life.

(Aus) I encourage people to interact with other people so we can remove the barriers between many race and understand their ethics background, because what I have learnt so far is what we think as Australian is not right it is right do to in China, and if we have a briefed 
or general idea about other people ethics we wouldn't have to underestimate people again and all will live happily.

(Aus) I went in, much like the other students with little knowledge on the Chinese culture, perceptions only created by what the news and television had to offer so I was a little skeptical, but the experience was an eye opener with their population so high their business seems extremely large scale in comparison to that of Australia's trade.

(Chn) We just learn everything we are asked to learn in China, but we often ignore the importance of what we need to learn.

(Aus) This study tour has benefitted my future career opportunities by giving me insight into how things are done overseas. I believe that this insight has improved my understanding of how much cultures can differ and feel that because of this, I will now be better in any field which I decide to go into once graduating, thanks to this Study Tour.

(Aus ) I've also gained experience working on a project with people in another country and this has given me a better understanding on what to expect when working internationally.

(Chn) To be honest, we benefit a lot from working with the Australian students, not only some knowledge, but also understand how to study.

(Aus) The Chinese have a lot of morals and respect for their culture and age differences. If you are older and or a higher status, you will be greeted with higher respect. I saw this when I was at the university when students greeted their teachers and their parents.

\section{Final Remarks}

For Australian and Chinese IT students, the development of professional skills, including crosscultural awareness, is as crucial as the development of technical skills. This article reported on the inaugural implementation of an approach aiming to enhance student cross-cultural awareness and "soft skill" development through a bi-national study experience supported by a contextual study of real-life IT scenarios.

Students participating in the study experience reported favourably on the impact of experience on their understanding and appreciation of different cultures in general, and the influence of culture on assessing and responding to IT related problems. Student responses seem to indicate an improved understanding of each other's culture and some shifts in perceptions and beliefs.

Student reflections provided a qualitative endorsement of the benefits of the approach and pointed out the pivotal role that the immersion within the target society and the opportunity to work in culturally mixed teams played in achieving the desired learning outcomes. This is a further confirmation that the use of formative assessment tasks and real-life IT scenarios is helpful in developing cultural awareness in students, but immersion and close cross-cultural contact have the potential to maximize the learning benefits.

Following the positive feedback on the study experience from students and academics, in Australia and China alike, it was considered worthwhile to embed the experience in the curriculum in future years. It was agreed that, to ease the financial demands on the participants, the study tours would alternate from year to year, or, if funding could not be secured, a virtual solution would be 
deployed. Consequently, in 2013 a cohort of Chinese participants from the Maritime University will come over to Victoria University.

\section{Acknowledgement}

The project outlined in this article has been supported by a 2011 Short Term Mobility Program grant from the Australian Department of Education, Employment and Workplace Relations.

\section{References}

Altback, P. G., \& Knight, J. (2007). The internationalization of higher education: Motivations and realities. Journal of Studies in International Education, 11(3-4), 290-305.

Boud, D., \& Falchikov, N. (Eds.). (2007). Rethinking assessment in higher education: Learning for the longer term. London: Routledge.

Department of Communications, Information Technology and the Arts. (2006). Building Australian ICT skills. Report of the ICT Skills Foresighting Working Group, Australian Government, Canberra. Retrieved February, 2012 from http://www.e-skills-ilb.org/docs/Building_Australian_ICTskills.pdf

Dwyer, M., \& Peters, C. (2004). The benefits of study abroad. Transitions Abroad, 27(5), 56-57.

Feng, G. Z., \& Hughes, J. (2009). Analyzing privacy and security issues in the information age - An ethical perspective. WSEAS Transactions on Information Science and Applications, 6(1), 126-135.

Forsey, M. G., Broomhall, S., \& Davis, J. (2011). Broadening the mind? Australian student reflections on the experience of overseas study. Journal of Studies in International Education, 20(10), 1-12.

Hutchings, K., Jackson, P., \& McEllister, R. (2002). Exploiting the links between theory and practice: Developing students' cross-cultural understanding through an international study tour to China. Higher Education Research \& Development, 21(1), 55-71.

Joseph, D., Boh, W. F., Ang, S., \& Slaughter, S. (2012). The career paths less (or more) traveled: A sequence analysis of IT career histories, mobility patterns, and career success. MIS Quarterly, 36(2), 427-452.

Kimmel, K., \& Volet, S. (2009). Significance of context in university students' (meta)cognitions related to group work: A multi-layered, multi-dimensional and cultural approach. Learning and Instruction, 20, 449-464.

Light, G., Cox, R., \& Calkins, S. (2009). Learning and teaching in higher education: The reflective professional (2nd ed.). Retrieved January, 2013 from

http://books.google.com.au/books?hl=en\&lr=\&id=E6oPmt8YuS0C\&oi=fnd\&pg=PP2\&dq=reflective + practice+Kolb+learning + experience + IT\&ots $=$ azB2-Dkeim\&sig $=-4 Z B-$

dMT Q2bKqQctkG8DrvEddU\#v=onepage\&q=reflective $\% 20$ practice $\% 20 \mathrm{Kolb} \% 20$ learning $\% 20$ experi ence $\% 20 I T \& \mathrm{f}=$ false

Multimedia Victoria. (2010). 2010 ICT skills snapshot report. Victorian Government, Department of Innovation, Industry and Regional Development, Melbourne.

Nunan, P. (2006). An exploration of the long term effects of student exchange experiences. Proceedings of the IDP Australian International Education Conference, Perth, Australia. Retrieved January 2013 from http://www.aiec.idp.com/pdf/Nunan\%20(Paper)\%20Thurs\%200900\%20MR5.pdf

Reynolds, M. (2011). Reflective practice: Origins and interpretations. Action Learning: Research and Practice, 8(1), 5-13.

Strang, K. D. (2010). Global culture, learning style, and outcome: An interdisciplinary empirical study of international university students. Intercultural Education, 21 6), 519-539.

Television for Education. (2012). Our region: Asia Pacific. Retrieved June 2012 from www.tveap.org/?q=our_region.php 
Trahar, S., \& Hyland, F. (2011). Experiences and perceptions of internationalisation in higher education in the UK. Higher Education Research \& Development (HERDSA), 30(5), 623-633.

Venables, A., Miliszewska, I., \& Tan, G. (2012). Information technology and society: An exchange of Australian and Chinese perspectives. Proceedings of the 9th International Conference on Cooperative Education and Work Integrated Learning (WACE) 2012 Istanbul, Turkey June 20-22, 2012. Retrieved from http://www.waceinc.org/bahcesehir2012/proceedings.html

\section{Biographies}

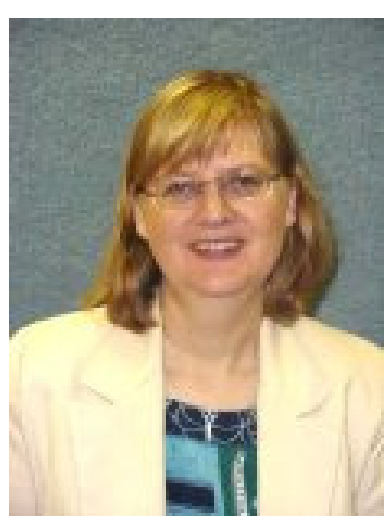

Anne Venables lectures in Computer Science and Information Technology at Victoria University, Melbourne, Australia. She has research and teaching interests in innovations in computing education and the application of intelligent systems in biological systems.

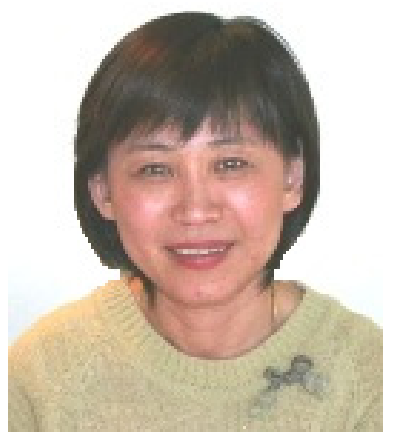

Grace Tan is a senior lecturer in Computer Science at Victoria University, Melbourne, Australia. Her research interests include investigations of innovative teaching methods, the development of graduate attributes, and issues related to female students in computing courses and Grace has published in these areas.

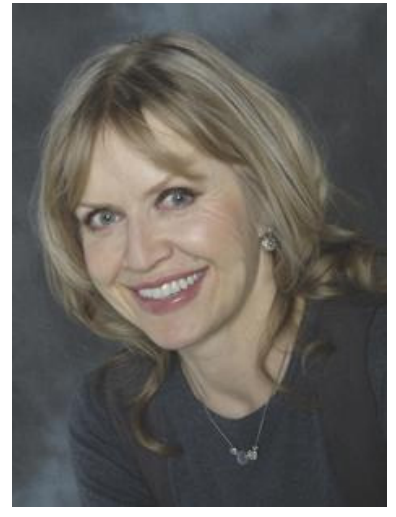

Dr Iwona Miliszewska is Associate Professor in computer science at Victoria University in Melbourne, Australia. She has led and participated in research projects involving transnational education, effective teaching methods, females in ICT, and technology supported learning and has published in these areas. 